\section{Visión Electrónica \\ Más que un estado sólido}

http: revistas.udistrital.edu.co/ojs/index.php/visele/index

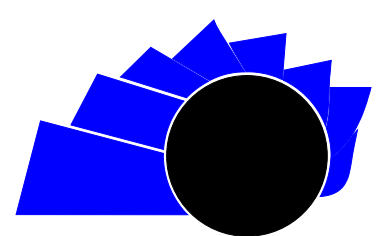

VISIÓN ELECTRÓNICA

\title{
Artificial neuronal networks for optical inspection in PCB quality control
}

\author{
Redes neuronales artificiales para inspección óptica en control de calidad \\ de $P C B$
}

Katherin Rodríguez Cadena ${ }^{1}$, Frank Nixon Giraldo Ramos. ${ }^{2}$

\section{INFORMACIÓN DEL ARTÍCULO}

Historia del artículo:

Enviado: 03/04/2017

Recibido: 01/06/2017

Aceptado: 12/08/2017

\section{Keywords:}

Artificial neural networks

Artificial vision

Automatic optical inspection

Printed circuit board

Quality management

\section{Open access

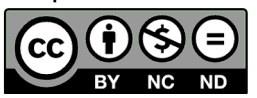

Palabras clave:

Redes neuronales artificiales

Visión artificial

Inspección óptica automática

Placa de circuito impreso

Gestión de calidad

\begin{abstract}
This paper is the result of the research work on the application of an artificial neural network algorithm applied in decision making in the process of AIO (Automatic Optical Inspection) for quality control from an electronic prototyping company, generating models for the assurance of Quality in the PCB (Printed Circuit Board) product, covering the fields of decision making, quality management, production processes, neural computer systems and artificial vision among others. It is intended to develop an algorithm of artificial neural networks that provides an approach to human recognition and perception when performing a quality inspection of the final product, based on image analysis and recognition. It is presented the theoretical concepts explored and the results obtained. Initially a problem definition was made to model, then the data processing was performed, the artificial neural network model was selected to be applied, then the relevant adjustments made to the model to finally obtain a simulation and validation of the same.
\end{abstract}

\section{RESUMEN}

Este trabajo es resultado de la investigación sobre la aplicación de un algoritmo de red neuronal artificial aplicado en la toma de decisiones en el proceso de AIO (Automatic Optical Inspection) para el control de calidad de una empresa de prototipado electrónico, generando modelos para garantizar la Calidad en el Producto de PCB (Printed Circuit Board), que abarca los campos de la toma de decisiones, la gestión de calidad, los procesos de producción, los sistemas informáticos neuronales y la visión artificial, entre otros. Su objetivo es desarrollar un algoritmo de redes neuronales artificiales que proporcione un enfoque para el reconocimiento y la percepción humana al realizar una inspección de calidad del producto final, basado en el análisis y reconocimiento de imágenes. Se presentan los conceptos teóricos explorados y los resultados obtenidos. Inicialmente se hizo una definición de problema para modelar, luego se realizó el procesamiento de datos, se seleccionó el modelo de red neuronal artificial para su aplicación, luego se realizaron los ajustes pertinentes al modelo para finalmente obtener una simulación y validación de los mismos.

\footnotetext{
${ }^{1}$ Sc. In Production, Universidad Distrital Francisco José de Caldas, Colombia. Current position: Analyst product coding, Arturo Calle, Colombia. E-mail: katrodriguezc@hotmail.com.

${ }^{2}$ BSc. In Electronic Control and Instrumentation, Universidad Distrital Francisco José de Caldas, Colombia. Current position: Professor Universidad Distrital Francisco José de Caldas, Colombia. Research group DIGITI, Universidad Distrital Francisco José de Caldas, Colombia. E-mail: fngiraldor@udistrital.edu.co.
} 


\section{Introduction}

A fundamental aspect of an organization's business strategy is to determine and enhance its competitive capacity, it is considered that competitive success in the market is achieved based on the continuous improvement of the quality of products and services offered. Quality implies meeting excellent standards, and as a competitive advantage is to exceed them [1].

In the process of developing electronic prototypes, the quality inspection of Printed Circuit Board (PCB) cards is an indispensable procedure that guarantees the quality and final functionality of the same, requiring verification of the specifications and parameters of the finished product. Therefore, the visual inspection of each elaborated PCB card must be carried out, which implies working time in the detection and correction of errors, and also because it is a routine and repetitive process, exhaustion of the operator, which can lead to errors or omissions in the verification and finally generate long prototyping times.

Getting a better quality product is part of a successful quality inspection, but if it is performed by the operator, he can present disadvantages and errors of perception due to his fatigue, diseases, optical disorders among others. Automatic visual inspection (AOI) consists on a non-destructive test, which applies artificial vision systems to compare and detect the types of defects and faults in a PCB. The application of artificial neural network algorithms and image recognition allows the inspection of more and more precise parameters, the AOI system must respond indicating the errors in a shorter time and more accurately than the human eye's abilities in this type of repetitive tasks.

Within the faults that AOI systems, they are able to detect the following groups:

- Vias defects:

Open tracks, short tracks, eroded tracks, inadequate track dimensions

- Welding defects:

Open circuits, welding bridges, short circuit welds, insufficient welding, excess welding

- Defects in components:

Pins or terminals lifted, Components lost, misaligned components and misplaced components

\section{Artificial neural networks}

Artificial Neural Networks, ANN (Artificial Neural Networks) are algorithms inspired by the biological neural networks of the human brain. They are formed mathematically model the behavior of a biological neuron and are shaped by elements similar to the biological neuron in their most common functions. These elements are organized in such a similar way to that presented by the human brain [2].

The fundamental element of a neural network is the "neuron", also called "node" or "elementary processor" PE, see figure 1 . In it, the sum of the $n$ inputs $x_{j}$ of neuron $i$ weighted with the synaptic weights $w_{i j}$, generates the total weighted input or "postsynaptic potential. ${ }^{\circ}$ neuron $i$. The synaptic weights $w_{i j}$ measure the intensity of the interaction between the two neurons that are connected by the link. Subsequently, an activation or transfer function $(f)$ applied to the difference between the "postsynaptic potential. ${ }^{a}$ nd the threshold $\theta_{i}$ the output of the neuron $\left(y_{i}\right)$.

Neurons are grouped in layers, and may or may not interact between neurons in the same layer. In turn, a set of layers forms a neural network, which can have two fundamental types of architecture; The feedforward where information is always transmitted forward, and the feedback architecture, in which information can be propagated backwards [3].

Figure 1: Standard model ANN.

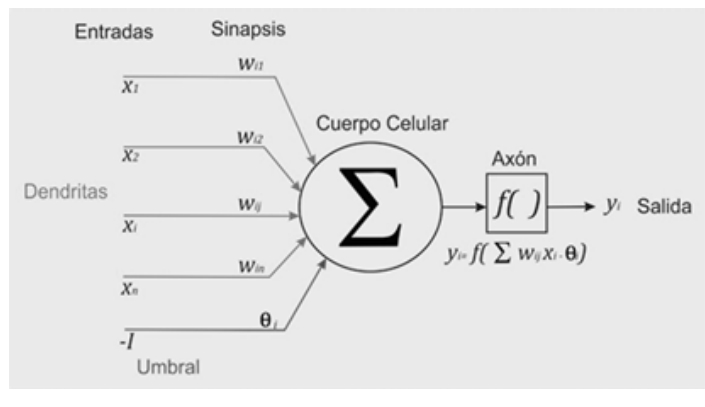

Source: Own.

Elements of a neuron:

- Set of inputs or vector of inputs $x$, of $n$ components.

- Set of synaptic weights $w_{i j}$ represent the interaction between the pre-synaptic neuron $j$ and the post synaptic $i$.

- Propagation rule $d\left(w_{i j}, x j(t)\right)$, proportional to post-synaptic potential, $h i(t)$

- Activation function $a_{i}(t)=f\left(a_{1}(t-i), h_{i}(t)\right)$ provides the state of activation of the neuron as a function of the previous state and the post-synaptic value. 
- Output function $F i(t)$ provides the output of $y_{i}(t)$, depending on the activation state [4].

A neural network consists of a set of elementary units $\mathrm{PE}$ connected in a specific way. The interest of ANNs lies not only in the model of the PE element but in the ways in which these processing elements are connected. Generally, PE elements are organized into groups called levels or layers. A typical network consists in a sequence of layers with connections between consecutive adjacent layers.

There are two layers with connections to the outside world. An input layer, input buffer, where the data is presented to the network, and an output buffer layer that maintains the network response to an input. The rest of the layers are called hidden layers. Figure 2 below shows the appearance of an Artificial Neural Network [2]

Figure 2: Components of ANN.

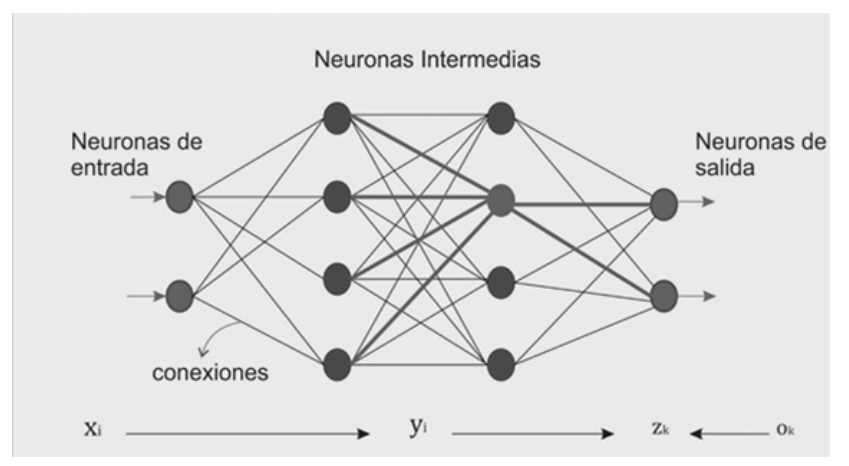

Source: Own.

These are the elements of an Artificial Neural Network:

- Input neurons (input layer)

- Output neurons (output layer)

- Intermediate neurons (hidden layers)

- Set of connections or synaptic weights between neurons

\section{The theory of adaptive resonance (ART)}

ART networks were designed, in particular to solve the "dilemma. of stability-plasticity: they are stable enough to preserve the most significant past learning, but they are not from the point of view of the incorporation of new informatics as soon as it appears.
With the term "Plasticityünderstood like: each system generates adaptive codes in response to a series of inputs from the environment. As learning about interactions between inputs and the system generates new stable states.

With the term "stability" which means that the learned codes should remain unchanged before the non-significant entries. The two above properties are intimately linked, since it is a system that must be able to adapt to new circumstances (plasticity), but also it must be stable enough, and not to be changed at the slightest variation $[5,6]$.

ART models can organize themselves in real time, producing stable recognition and keeping input patterns within categories originally saved.

To solve the dilemma of plasticity and stability, the ART model proposes to be added to the networks a feedback mechanism between the competitive neurons of the network output layer and the input layer.

This mechanism facilitates the learning of new information without destroying the one already stored. The theory of adaptive resonance is based on the idea of doing.

Resonate the input information with the representatives or prototypes of the categories that the network recognizes. If it resonates with one, it is sufficiently similar, the network considers that it belongs to that category and it only makes a small adaptation of the stored prototype representative of the category to incorporate some characteristics of the data presented. When it does not resonate with any, it does not resemble any of the existing ones, remembered by the network until that moment, the network is responsible for creating a new category with the input data as a prototype of it.

ART networks are made up of a subsystem of caring and a guiding subsystem. Figure 3.

The attention subsystem contains: Two competitive neurons: the comparison layer F1 and the recognition layer F2 and two gain controls.

The steering subsystem contains the reset layer that is in charge of controlling the dynamics of the subsystem of attention. 
Figure 3: Attention subsystem.

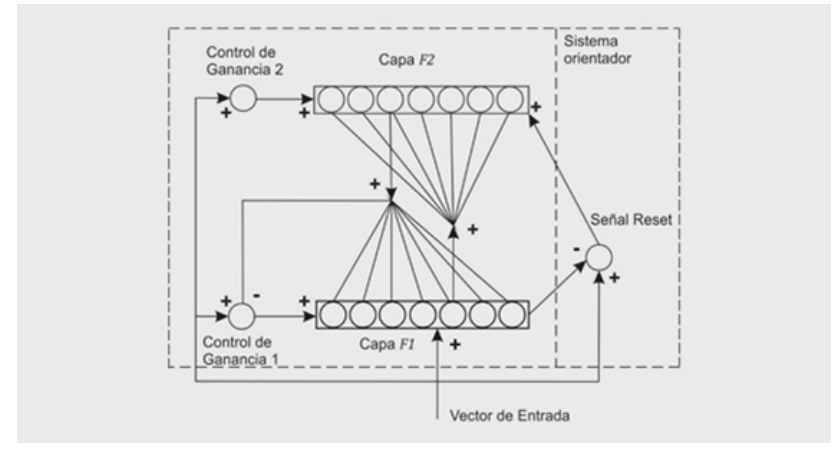

Source: Own.

The plus sign indicates an excitatory connection and the minus sign an inhibitory connection. The activity patterns that develop above the nodes in the two layers of the attention system are called short-term memory (STM) because they only exist in association with a single application of the input neuron. The weights associated with the Bottom up and Top-Down between F1 and F2 are called long-term memory (LTM) because they encode the information that remains for a long period of time. Stabilization of learning and activation occurs in the attention subsystem, with the activation of the input (Bottom-Up) and the comparison (TopDown) [7].

\section{1. $\quad$ Red ART2}

ART2 networks were designed, in particular, to solve the stability-plasticity dilemma, the architecture of ART2 are designed for the processing of analog inputs as well as binary components. This capability represents an enhancement to the system.

ART2 must be able to recognize the underlying similarity of identical overlapping patterns in constant backgrounds having different levels. Compared in a common sense, two similar patterns must appear entirely different when in fact, the same pattern must be classified.

\subsection{Processing Methodology of ART2}

Only asymptotic solutions are considered for the dynamic equations, and the mode of rapid learning. $\mathrm{M}$ is going to be the number of units in each sublayer F1, and $\mathrm{N}$ will be the number of units in F2. The vestments are chosen according to the following restrictions

$$
\begin{aligned}
a, b & <0 \\
0 \leq d & \leq 1 \\
\frac{c d}{1-d} & \leq 1 \\
0 \leq c & \leq 1 \\
0<p & <1 \\
e & \ll 1
\end{aligned}
$$

Top-Down weights are started at zero

$$
Z_{i j(0)=0}
$$

Bottom-Up weights are initialized according to

$$
Z_{i j}(0) \leq \frac{1}{(1-d) \sqrt{M}}
$$

Data processing starts

1. Itialize all the outputs of the layers and sublayers in vectors zero and set a counting cycle initialized to a value of one.

2. Apply an input pattern $I$ to the layer $w$ of F1. The output of this layer is:

$$
w_{i}=I_{i}+a u j
$$

3. Propagate to the sublayer $x$ :

$$
x_{i}=\frac{w_{i}}{e+\|w\|}
$$

4. Propagate to the sublayer v:

$$
v_{i}=f\left(x_{i}\right)+b f\left(q_{i}\right)
$$

Note that the second term is zero through the first step, as well as zero for that time

5. Propagate to the sublayer u:

$$
u_{i}=\frac{v_{i}}{e+\|v\|}
$$

6. Propagate to the sublayer $\mathrm{p}$ :

$$
p_{i}=u_{i}+d Z_{i j}
$$

Where the $\mathrm{J}$ node in $\mathrm{F} 2$ is the winner of the competition in that layer. If F2 is inactivated, $p_{i}=u_{i}$. Similarly, if the network is still in its initial configuration, $p_{i}=u_{i}$ because $Z_{i j}(0)=0$

7. Propagation towards the sublayer $q$ :

$$
q_{i}=\frac{p_{i}}{e+\|p\|}
$$

8. Repeat from the second step to the seventh as many times as necessary to stabilize the values in F1 
9. Calculate the output of layer $r$ :

$$
r=\frac{u_{i}+c p_{i}}{e+\|u\|+\|c p\|}
$$

10. Determine if a reset condition is indicated. If $p /(e+$ $\|r\|)>1$, then send a reset signal to F 2 . Mark any active F2 node as ineligible for competition, reset the cycle counter to one, and return to step two. If there is no reset, and the cycle counter is one, increasing the cycle counter and continue step 11. If there is no reset, and the cycle counter is larger than one, then skip to step 14, where one Resonance has been established.

11. Propagate the output of the sublayer $\mathrm{p}$ to the layer F 2 . Calculate the network inputs for $\mathrm{F} 2$.

$$
T_{j}=\sum p_{i} Z_{i j}
$$

12. Only the winning node F2 has an output other than zero.

$$
g\left(T_{j}\right)= \begin{cases}d & T_{j}=\frac{\operatorname{Max}}{k}\left[T_{k}\right] \\ 0 & \text { otro valor }\end{cases}
$$

All nodes marked as ineligible by the previous reset signals do not participate in the competition

13. Repeat steps 6 through 10

14. Unify the Botton-Up weights on the winning F2 unit

$$
Z_{j i}=\frac{u_{i}}{1-d}
$$

15. Modify the Top-Down weights on the winning F2 unit.

$$
Z_{i j}=\frac{u_{i}}{1-d}
$$

16. Remove the input vector. Restore all inactive F2 drives. Return to step one with a new pattern [8]

\section{Methodology for Automatic Visual Inspection (AOI):}

The visual inspection performed by an operator of each PCB is not free of human errors, due to the fatigue of the operator who performs the revision, in addition to requiring a lot of time, consequently costs. Therefore, a computer-based automatic inspection system based on artificial vision that allows the detection and classification of defects in a printed circuit board in Matlab, seeks to improve the classification of defects

The manufacturing process of PCBs is made from chemical and mechanical actions, which can damage the design of the PCB during the production phase. Any anomaly between the original design delivered by the CAD software and the actual images captured from the PCB show and allow to classify the defects.

Among the most frequent types of defects in PCBs such as track rupture, open circuits, short circuits, bites in tracks and erosions in tracks.

The images of the PCB delivered by the CAD software in the design phase can be used as standard images to compare them with the images taken from the actual form to automatically evaluate any defects.

Image pattern recognition has been used commercially for many years in order to identify faults, and also to control the automatic placement of components in the printed circuit. However, most of the techniques currently in use are proprietary and are designed for large- scale operations.

For small-scale manufacturers that do not have access to complex vision technology or expensive vision systems, there are few options. They are often forced to perform manual inspections that require long hours of work.

The aim of this study is to develop a cost-effective solution for small PCB manufacturers. In addition, the solution should not be based on patented image processing techniques. It should not be sensitive to adjustments and do not require frequent calibration or manual adjustment. In addition, this solution should not rely on the board, which means that the solution can be easily used for different types of PCB.

Once the PCB is made in some CAD design software, three masks must be obtained to be able to perform the revision and comparison as patterns: path masking, component masking and welding mask (Figure 4).

Figure 4: Printed circuit designed in CAD software.

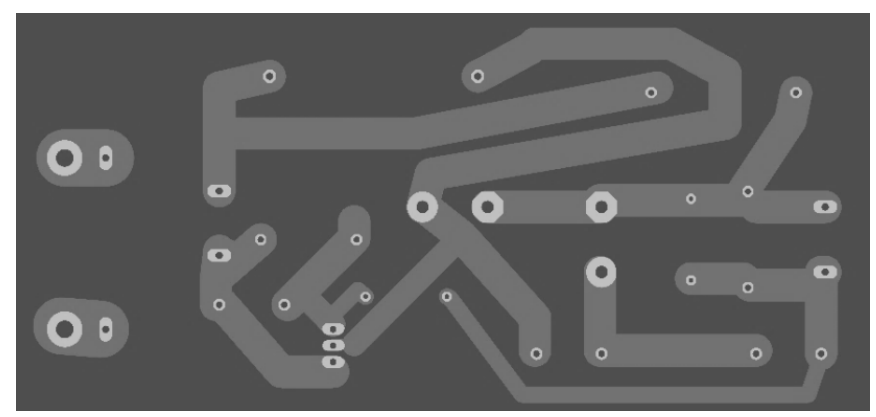

Source: Own. 
Figure 5: Soldermask.

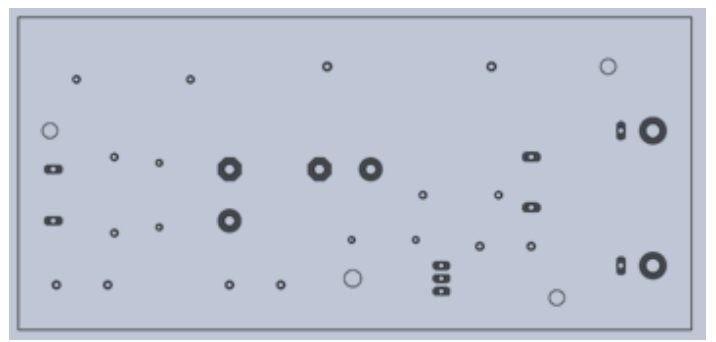

Source: Own.

Figure 6: PCB vías mask.

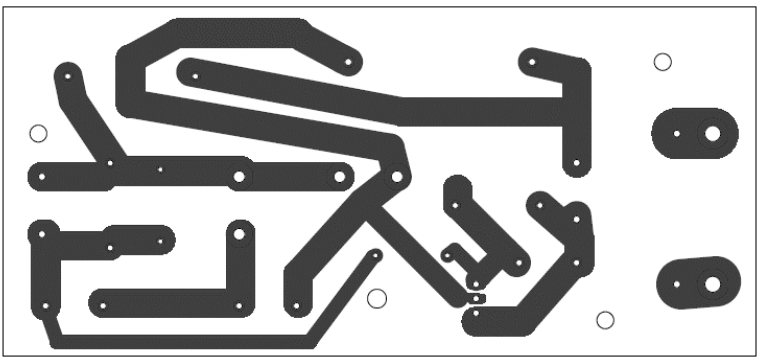

Source: Own.

Figure 7: Components mask.

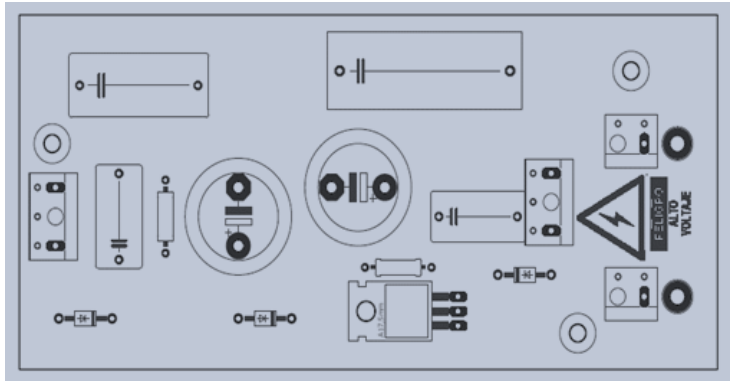

Source: Own.

Visual inspection should be performed on each of the masks to identify faults in the tracks and positioning of the components.

Once the PCB is finished, it must be visually inspected. For this purpose, the first phase of the AOI process is carried out with a common scanner, in order to capture the image of the obtained PCB (Figure 8).
Figure 8: Corresponding scanned printed circuit.

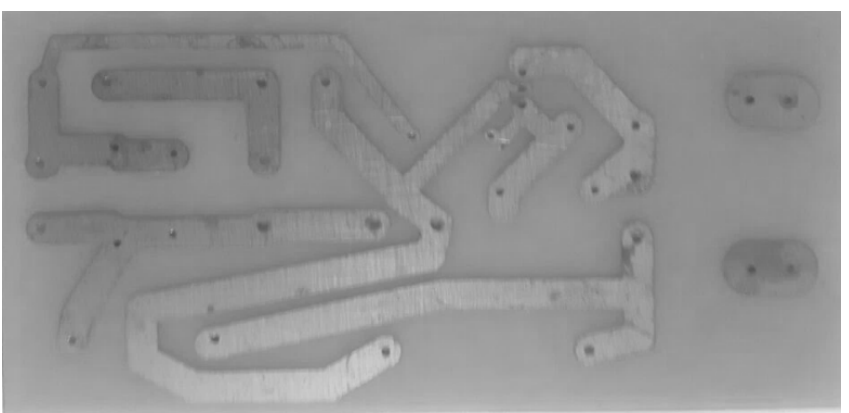

Source: Own.

The following part should identify the type of video adapter installed in the system:

imaqhwinfo

ans $=$

InstalledAdaptors: \{'coreco' 'winvideo'\}

Then you must determine the video capture formats supported by the chosen adapter:

dev_info = imaqhwinfo('winvideo',1)

celldisp(dev_info.SupportedFormats)

It selects an adapter and one the capture formats supported in this case 640 by 480 YUY2:

vid = videoinput('winvideo',1,' YUY2_640x480');

Video capture starts:

start(vid);

preview(vid);

A photograph of the PCB is taken:

imagen $=$ getsnapshot $($ vid $)$;

Grayscale conversion is performed:

img_grises =rgb2gray(imagen);

Figure 9: Grayscale conversion.

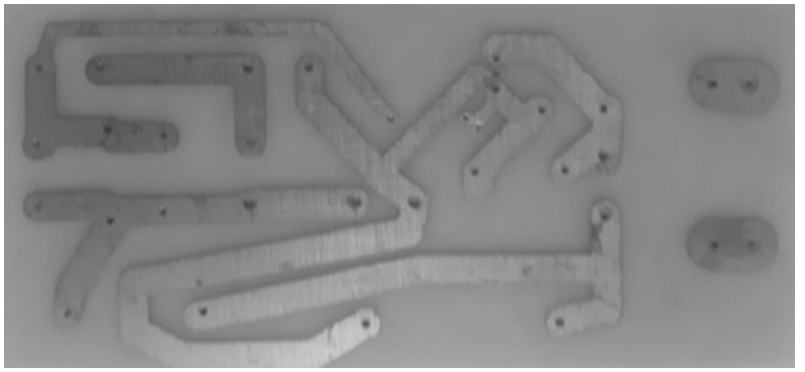

Source: Own. 
Figure 10: Adjust grayscale.

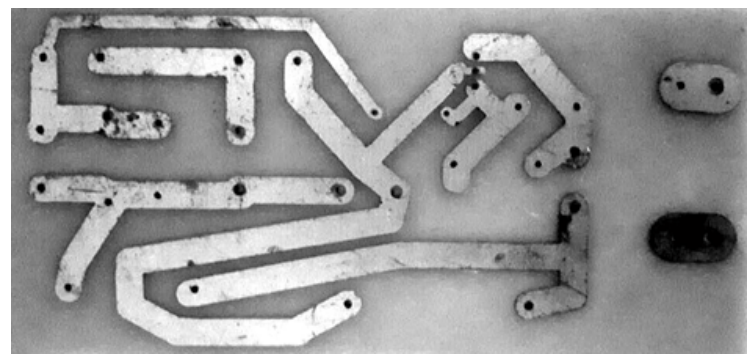

Source: Own.

Adjust grayscale for better image definition: img_adj_contraste $=$ imadjust(img_grises);

The conversion is done in black and white with a threshold of 0.51 in this case:

imagen_bw $=$ im2bw (img_adj_contrast,0.51);

It complements the image to get the positive:

imagen_bw = imcomplement (imagen_bw);

Figure 11: Positive.

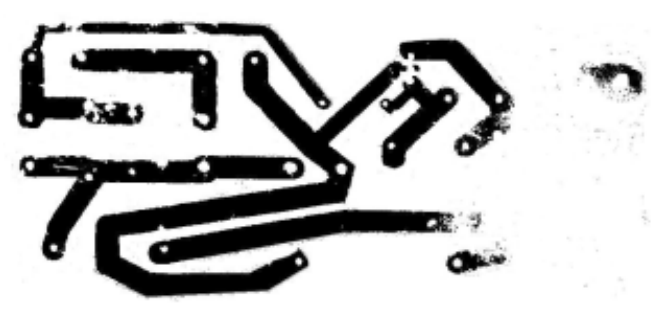

Source: Own.

Figure 12: Pattern image for comparison taken from CAD software.

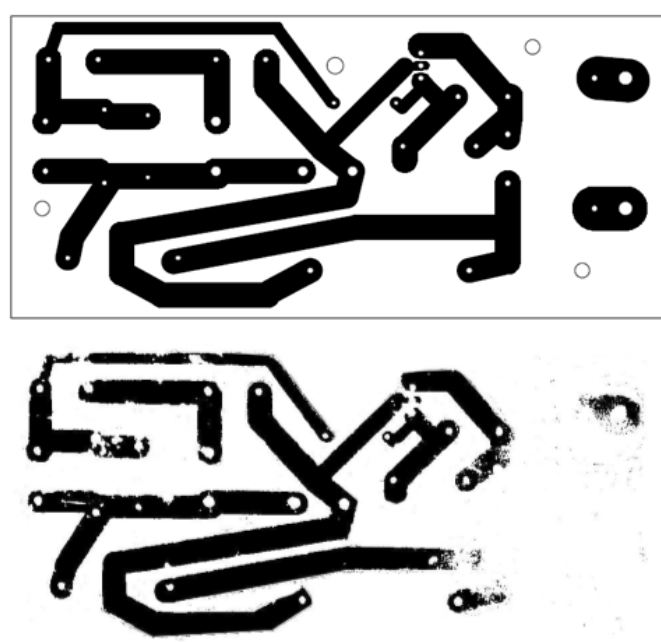

Source: Own.
An untrained network must be created by defining the input data vector $(X)$ corresponding to the image to be tested and the target vector $(T)$ corresponding to the PCB pattern:

$$
\begin{array}{r}
>>X \\
>>T \\
>>\text { nntool }
\end{array}
$$

Figure 13: ANN structure.

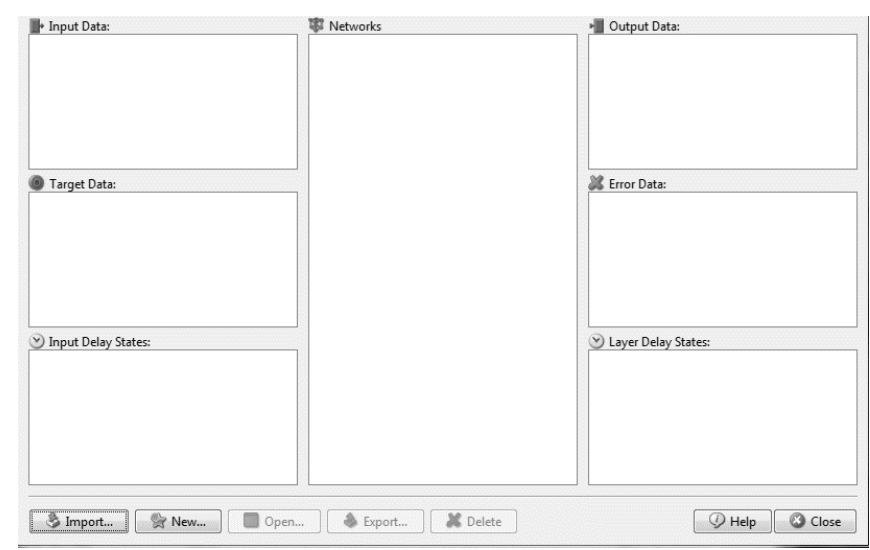

Source: Own.

Select import to enter the vectors: We import $X$ as input (Figure 14):

Figure 14: Input vector.

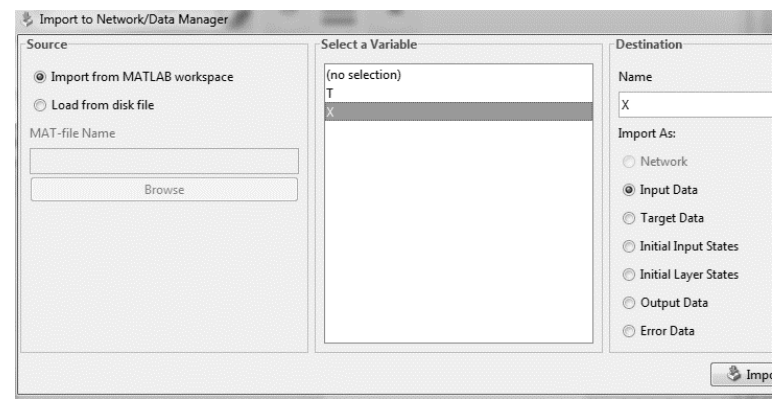

Source: Own.

We import the target $T$, as target (Figure 15): 
Figure 15: We close and in the neutral network indicated here.

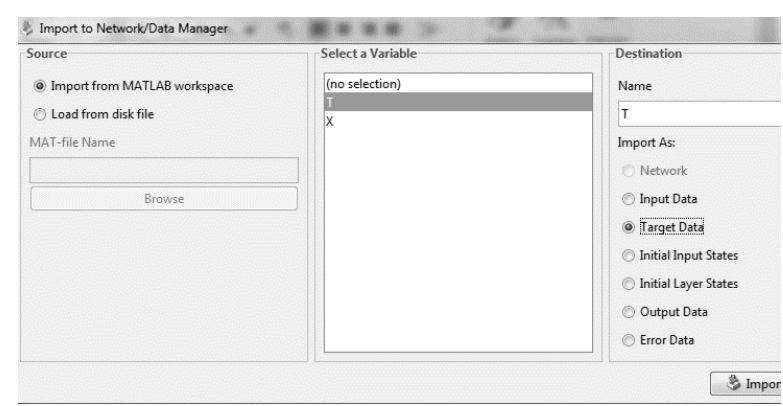

Source: Own.

Figure 16: New button we create configuring it as.

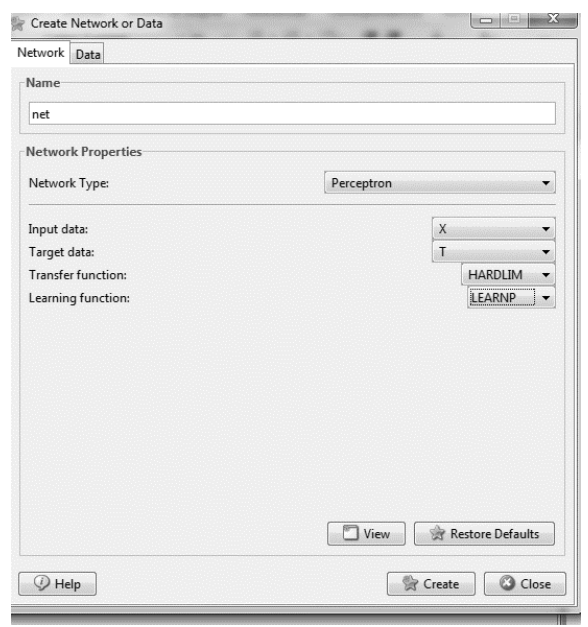

Source: Own. 17)

We create it, close it and in the export button (Figure

Figure 17: Data Manager Export ANN model.

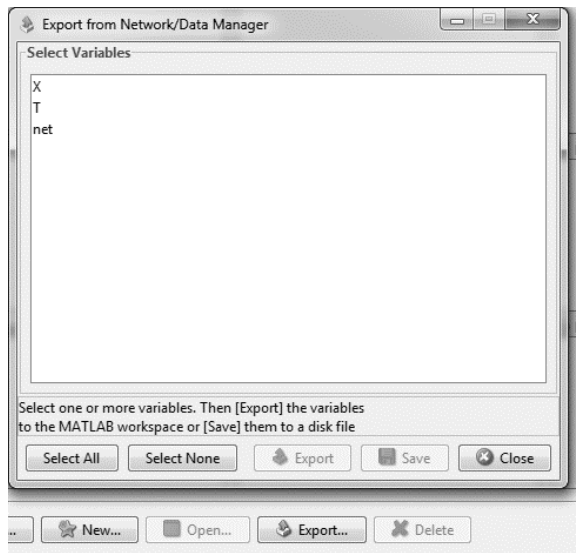

Source: Own.
We select the network and export it to Workspace. We can see it

$>\operatorname{view}($ net $)$

And we can simulate it:

$>>Y$ net $=\operatorname{sim}($ net,$X)$

As the neural network is untrained, proceed to the training phase by entering different images to verify, with different types of faults or defects

Training:

$>>$ net.trainParam.epochs $=1000 ;$ \%iterationsnumber

$>>$ net $=\operatorname{train}($ net $, X, T) ; \%$ training

$>>Y$ net $=\operatorname{sim}($ net,$X) \%$ weights

CREATINGTHENETWORKWITHNFTOOL :

$>>$ ftool

Figure 18: NNTool interface.

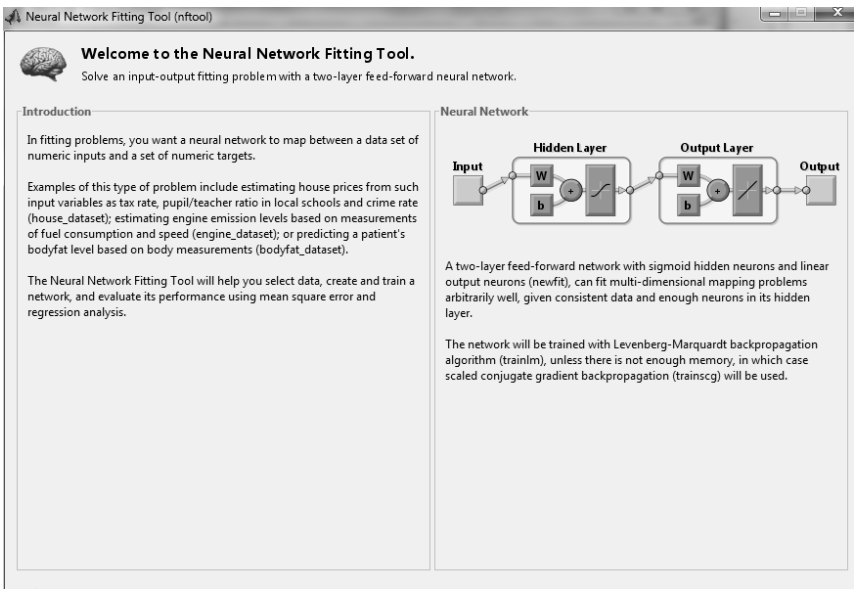

Source: Own.

The input and target data are chosen (Figure 19) 
Figure 19: Inputs and Target selection.

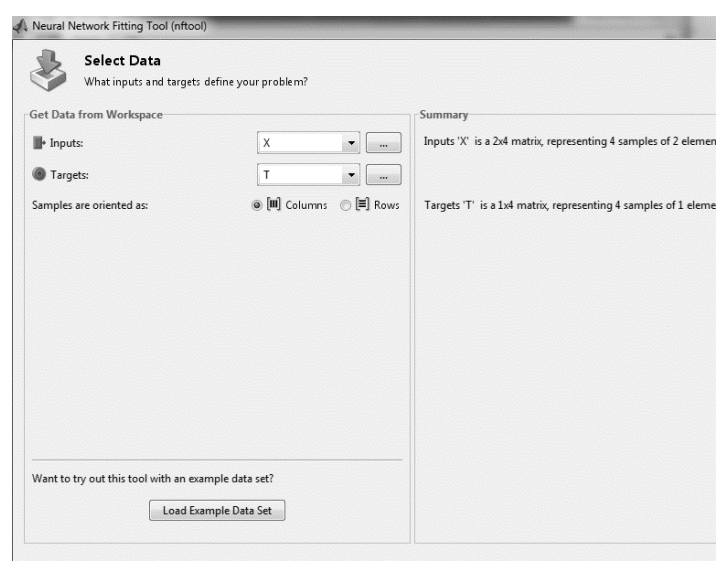

Source: Own.

The default settings are left(Figure 20):

Figure 20: Fitting settings.

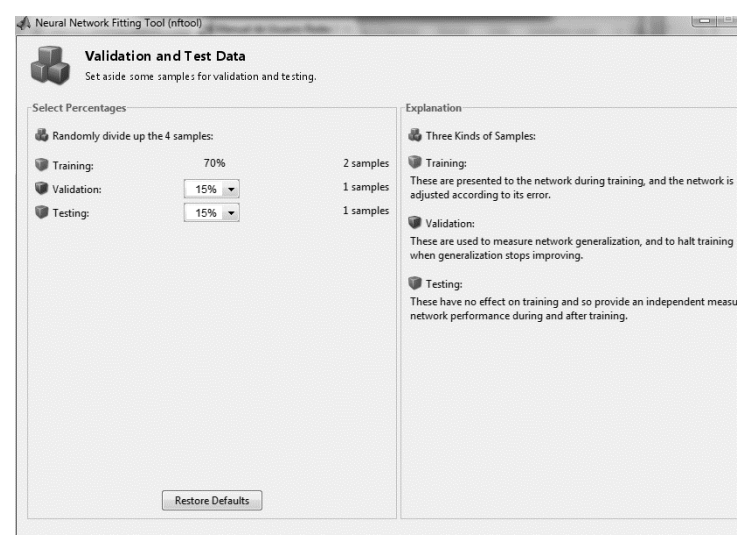

Source: Own.

It defines the size of the network for the case a neuron (Figure 21)

Figure 21: ANN Sizing.

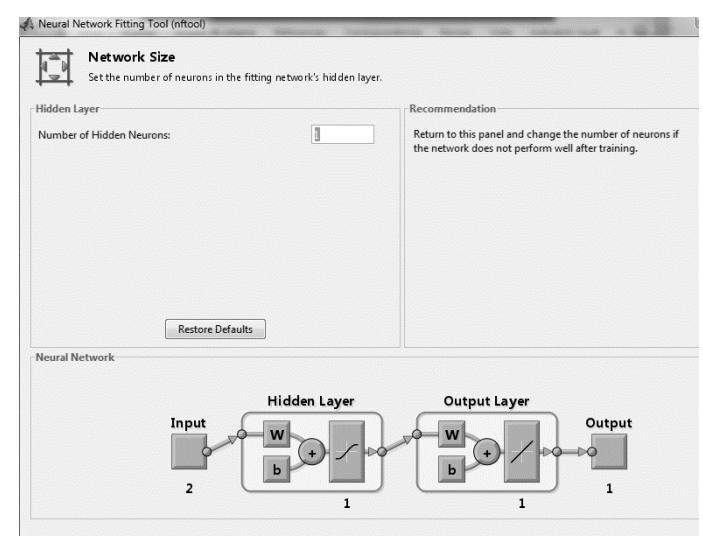

Source: Own.

The training is performed(Figure 22):

Figure 22: Training and fitting.

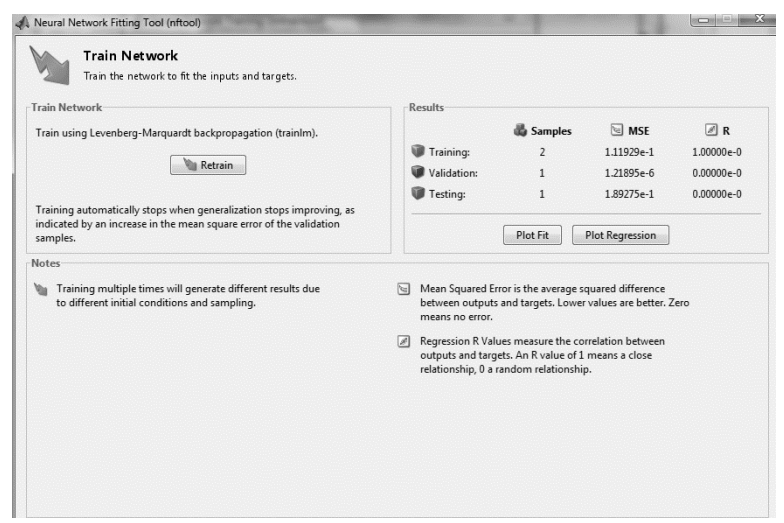

Source: Own.

Figure 23: ANN validation phase.

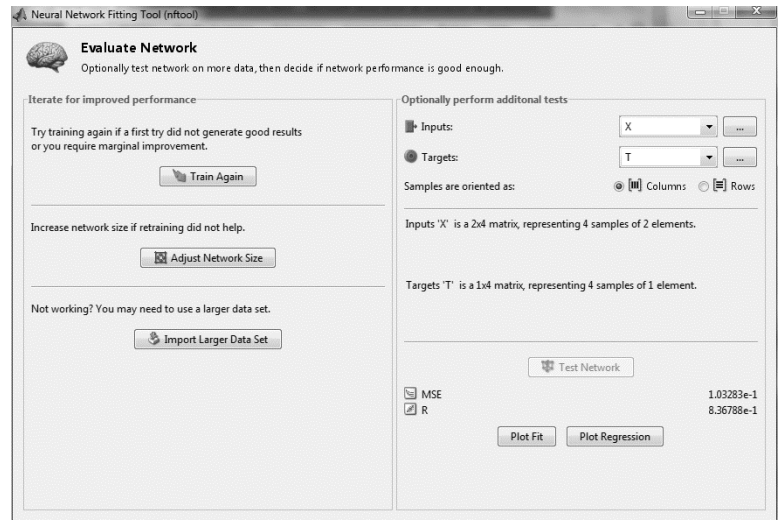

Source: Own.

We generate the m-file to run the network, which generates the function of our network ready to enter inputs and outputs

And we generated the network in Simulink to export the network to Simulink (Figure 24).

And we tested the function: $>>$ create_fit_net $(X, T)$

\section{Conclusions}

This paper evaluated a methodology for detecting defects in PCBs from image processing. Performing the identification and real-time classification of the defects of a prototype PCB by means of digital image processing. Faults can be identified even before the components are soldered on the PCB. 
Figure 24: Fiiting phase ANN.

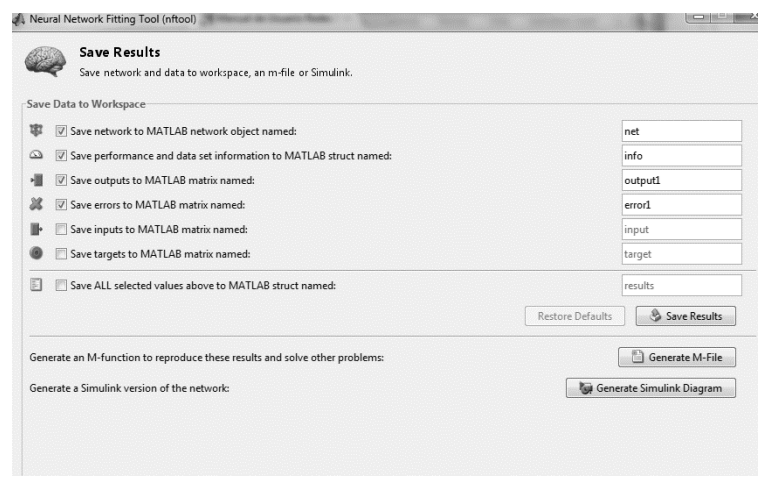

Source: Own.

Classification efficiency and execution speed make this classifier a low-cost solution, both technically and economically, allowing it to be used in a variety of environments (such as schools, ministries and households) and in multiple services (e-mail, web browsing, transfer and storage of documents, among others).

\section{References}

[1] B. Salazar, "Gestión y control de la calidad" February 20 th 2017 [Online] Available: https://www.ingenieriaindustrialonline.com/ herramientas-para-el-ingeniero-industrial/ gesti\%C3\%B3n-y-control-de-calidad/

[2] X. Basogain, "Redes neuronales artificiales y sus aplicaciones, escuela superior de ingeniería de Bilbao" February 20 th 2017 [Online] Available: http://www. ciberesquina. una.edu.ve: 8080/2014_2/350_E.pdf

[3] P. Priore, D. de la Fuente, R. Pino, J. Puente, "Utilización de las Redes Neuronales en la toma de decisiones. Aplicación en un problema de secuenciación" anales de mecánica y electricidad". noviembre-diciembre, 2002, p. 28.

[4] H. Vega, "Redes neuronales para el reconocimiento de la calidad morfológica de mangos exportables para la empresa Biofruit del Perú S.A.C". February 20 th 2017 [Online] Available: http://cybertesis. unmsm.edu.pe/bitstream/ cybertesis/1521/1/Vega_hh.pdf
[5] Portafolio Digital "Introducción a la inteligencia artificial" [Online] Available: https: //inteligenciaartificialkarlacevallos. wordpress . com/2014/10/08/ introduccion-a-la-inteligencia-artificial/

[6] R. Pino, A. Gómez, N. Abajo, 2001, "Introducción a la inteligencia artificial: sistemas expertos, redes neuronales artificiales y computación evolutiva", Universidad de Oviedo servicio de publicaciones.

[7] Cubas Glenn G, Borre del rio O, 2007, "Estudio y aplicaciones de las redes ART (Teoría de la resonancia adaptativa)", Universidad Tecnológica de Bolívar, p. 71 .

[8] Cubas Glenn G, Borre del rio O, 2007, "Estudio y aplicaciones de las redes ART (Teoría de la resonancia adaptativa)", Universidad Tecnológica de Bolívar, p. 82.

[9] S. H. Indera Putera and Z. Ibrahim, "Printed Circuit Board Defect Detection Using Mathematical Morphology and MATLAB Image Processing Tools", ICINT 2010, Shanghai, China, https://doi.org/ 10.1109/ICETC. 2010.5530052

[10] M. Moganti, F. Ercal, C. H. Dagli and S. Tsunekawa "Automatic PCB inspection algorithms: A survey", Computer Vision and Image Understanding, vol.63, no.2, 1996, https://doi.org/10.1006/cviu.1996. 0020

[11] R. Heriansyah, S.A.R Al Attas, and M.M. Ahmad Zabidi, "Segmentation Of PCB Image into Simple Generic Pattern using Mathematical Morphology And Windowing Technique", CoGRAMM Melaka, Malaysia, 2002.

[12] R. Heriansyah. "Classification of Defect on Bare PCB using Neural Network Technique", Master Thesis, Universiti Teknologi Malaysia, 2004.

[13] Y. Hara, N. Akiyama, and K. Karasaki. "Automatic Inspection System for Printed Circuit Boards." IEEE Transactions on Pattern Analysis and Machine Intelligence. Vol. PAMI- 5. No. 6. 623 - 630, https: //doi.org/10.1109/TPAMI.1983.4767453

[14] Wu, Wen-Yen, Mao-Jiun, J. Wang and Chih-Ming, Liu. "Automated Inspection of Printed Circuit Boards Through Machine Vision." Computers in Industry. vol. 28. Issue 2. 103 - 111, 1996. 